\title{
Optimization of onion Juice inhibiting white-blush in fresh-cut carrots by response surface methodology
}

\author{
Jiani $\mathrm{Lu}^{1 *}$, Xiaoning Jiang ${ }^{2}$ \\ ${ }^{1}$ Food Science and Engineering College, Beijing University of Agriculture, Beijing, 102206, China; \\ ${ }^{2}$ RDFZ Xishan School, Beijing, 100193, China
}

\begin{abstract}
The effect of onion juice on the whitening of fresh-cut carrots during storage was explored to optimize the processing technology of fresh-cut carrots. Using fresh carrot and onion as raw materials and whiteness value as reference index, the process parameters were optimized by response surface methodology (RSM) based on single factor experiment, and the physiological and biochemical indexes were determined. Results showed that the process conditions optimized by response surface processing of fresh-cut carrot onion were as follows: the concentration of the onion juice for $75 \%$, soaking time for $15 \mathrm{~min}$, spin-drying time for $60 \mathrm{~s}$. Under this condition, for the fresh-cut carrot, whiteness value theoretical value was 30.51 , and the actual whiteness value was $31.26 \pm 0.5$. After verification, the model was established and the fit worked well. The quality of fresh-cut carrots treated with onion juice was better. This study laid a scientific foundation for the inhibition of whitening of fresh-cut carrot.
\end{abstract}

\section{Introduction}

Carrot (Daucas Carota L.), also known as yellow radish and clove radish, has the reputation of "soil ginseng" and "golden shoot" for its unique flavor, rich nutritional value and health function ${ }^{[1]}$. However, due to dehydration and lignification, the surface of fresh-cut carrot becomes white during storage and loses its characteristic bright yellow color, which limits the development of carrot. Therefore, it is necessary to use appropriate technology to restrain the whitening of fresh-cut carrots and prolong the shelf life of fresh-cut carrots.

There are also many studies on whitening of fresh-cut carrots. The results of Ren Lifang ${ }^{[2]}$ showed that $0.6 \%$ citric acid and $0.4 \%$ ascorbic acid had the best effect on reducing the whiteness of fresh-cut carrots. In the study of Chen et $\mathrm{a}^{[3]}$, the whiteness of fresh-cut carrot treated with $\mathrm{H}_{2} \mathrm{~S}$ was significantly inhibited, and the content of $\mathrm{H}_{2} \mathrm{O}_{2}$ and MDA in fresh-cut carrot was decreased, at the same time the activity of lignin synthesis-related enzymes(PPO, POD and PAL) were reduced and the activities of antioxidant enzymes in fresh-cut carrots were increased, which was due to $\mathrm{H}_{2} \mathrm{~S}$ can effectively remove reactive oxygen species in fresh-cut fruits and vegetables, strengthen antioxidant defense system and reduce oxidative damage. Onions contain a lot of sulfur compounds, mainly disulfide and trisulfide ${ }^{[4]}$. Studies ${ }^{[4]}$ indicated that disulfide and trisulfide could inhibit the activity of PPO and POD enzymes in fruits and vegetables, which provided a theoretical basis for the inhibition of whitening of fresh-cut carrots by onion juice. Onion juice is a natural extract with non-toxic, harmless and natural characteristics, so it is necessary to study the technology of inhibiting the whitening of fresh-cut carrot with onion juice.

Fresh carrots and fresh onion were used as raw materials to design a single factor experiment. Based on the results of single factor experiment, the onion juice treatment process of fresh-cut carrots was optimized by response surface method, and the best process parameters were obtained. The effect of this study laid a certain foundation for the research of inhibiting fresh-cut carrots.

\section{Experimental materials, reagents and instruments}

\subsection{Main materials}

Carrots and Onions were bought from farmers' markets.

\subsection{Main reagents and instruments}

Sulfuric acid, phosphoric acid, all from Beijing Chemical Plant; Hydrogen peroxide, Tianjin BASF Chemical Co., Ltd.; Boric acid, Shanghai McLean Biochemical Technology Co., Ltd.; Trichloroacetic acid, Sinopharm Chemical Reagents Co., Ltd.

Chromatic aberration instrument, Shanghai Gaozhi Precision Instrument Co., Ltd. UV-Vis Spectrophotometer, Shanghai Precision Instrument Co., Ltd.; Electronic Balance, Sartorius Scientific Instruments (Beijing) Co., Ltd.; Electric heating constant temperature blast drying oven, Tianjin Zhonghuan Experimental Electric Furnace Co., Ltd.

*Corresponding author’ E-mail: twentyone77@163.com 


\section{Test Methods}

\subsection{Sample handling}

(1) Choosed fresh, pest-free carrots of the same size and quality, peeled them and cut them into $2 \mathrm{~cm}$ thick chunks, cleaned them with water, dried them, and set them aside.

(2) Preparation of onion juice: in a sterile environment, the onion was peeled and cut into pieces, put the juice in a juicer, and the sterilized four-layer gauze was filtered aseptically on the ultra-clean worktable to get the onion stock solution with a concentration of $100 \%$, and then diluted with deionized water for reserve.

(3) Single factor test: different concentration of onion juice, different soaking time and different spin-drying time were used to carry out single factor test on fresh-cut carrots to screen out the appropriate concentration, appropriate soaking time and appropriate spin-drying time. Based on the single factor experiment, the response surface was designed, and the process was optimized to determine the optimal processing parameters of onion juice for fresh-cut carrots.

\subsection{Determination of whiteness value}

Referring to the method of Bolin ${ }^{[5]}$ et al. 4

\subsection{Determination of PAL}

Refer to Sun Guangyu ${ }^{[6]}$ Methods.

\subsection{Determination of lignin content}

Refer to the Luo ${ }^{[7]}$ Methods.

\subsection{Data processing}

The obtained data were analyzed and processed by Origin 8.5 software, and each group of data was measured in parallel for three times. The significance analysis was conducted by SPSS software and the analysis was conducted by Desking-Expert 12.0 software.

\section{Results and analysis}

\subsection{Single factor experiment of onion juice treatment of fresh-cut carrot}

4.1.1 Influence of onion juice concentration on whiteness value of fresh-cut carrots

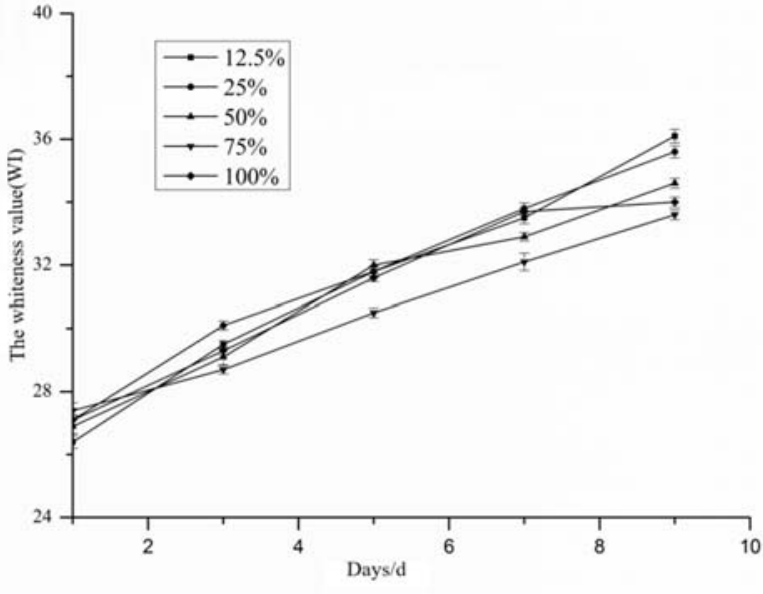

Figure 1. Effect of different concentrations on whiteness of fresh-cut carrots

It can be seen from Figure 1 that the whiteness value of fresh-cut carrots showed a trend of gradual increase, and the increase tended to be stable at the later stage of storage. When the onion concentration was $75 \%$, the whiteness value of fresh-cut carrot was the lowest, followed by the onion juice with $100 \%$ and $50 \%$ concentration. With the whiteness value as the reference index, the onion juice with $75 \%$ concentration was selected as the research concentration in this experiment.

\subsubsection{Influence of soaking time on whiteness value of fresh-cut carrots}

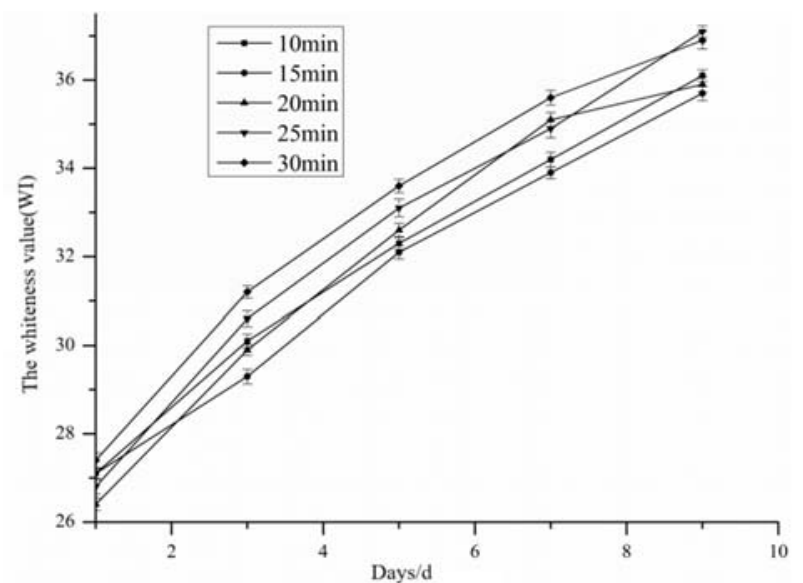

Figure 2. Effect of different soaking time on whiteness of fresh-cut carrots

As seen from Figure 2, with the increase of storage days, the whiteness value of fresh-cut carrots was increasing. With the change of soaking time, the whiteness value of fresh-cut carrots changes. It can be seen from Figure 2 that the whiteness value of fresh-cut carrots was the lowest when soaking time was $15 \mathrm{~min}$, followed by the whiteness value of fresh-cut carrots when soaking time was $10 \mathrm{~min}$ and $20 \mathrm{~min}$. With the whiteness value as the reference index, $15 \mathrm{~min}$ was selected as the soaking time in this study. 


\subsubsection{Influence of drying time on whiteness value of} fresh-cut carrots

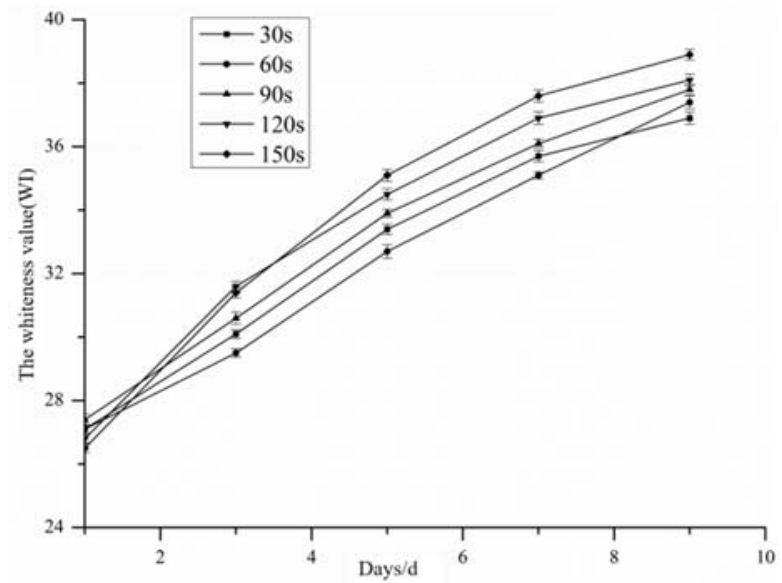

Figure 3. Effect of different drying time on whiteness of fresh-cut carrots

It can be seen from Figure 3 that the whiteness value of fresh-cut carrot was an upward trend in whole. When the drying time was $60 \mathrm{~s}$, the whiteness value of fresh cut carrot in storage was the lowest in five time periods, which increased gentlest. With fresh cut carrot whiteness value as reference index, the selection test dry time $60 \mathrm{~s}$ as the research target.

\subsection{Response surface test design and results}

Table1. Factors and levels of response surface design

\begin{tabular}{|c|c|c|c|}
\hline \multirow{2}{*}{$\begin{array}{l}\text { Level } \\
\text { number }\end{array}$} & \multicolumn{3}{|c|}{ Factor } \\
\hline & $\begin{array}{c}\text { Concentrati } \\
\text { on } / \%\end{array}$ & $\begin{array}{l}\text { Soaking } \\
\text { time/min }\end{array}$ & $\begin{array}{c}\text { Spin-drying } \\
\text { time/s }\end{array}$ \\
\hline-1 & $50 \%$ & 10 & 30 \\
\hline 0 & $75 \%$ & 15 & 60 \\
\hline 1 & $100 \%$ & 20 & 90 \\
\hline
\end{tabular}

Table2. Response surface optimization test results

\begin{tabular}{|c|c|c|c|c|}
\hline \multirow[b]{2}{*}{$\begin{array}{l}\text { Serial } \\
\text { number }\end{array}$} & \multicolumn{3}{|c|}{ Factor } & \multirow[b]{2}{*}{$\begin{array}{l}\text {-Whitenes } \\
\text { s value }\end{array}$} \\
\hline & $\begin{array}{c}\text { A:Concentratio } \\
\mathrm{n}(\%)\end{array}$ & $\begin{array}{l}\text { B:Soaking } \\
\text { time (min) }\end{array}$ & $\begin{array}{c}\text { C:Spin-drying } \\
\text { time (s) }\end{array}$ & \\
\hline 1 & 50 & 10 & 60 & 30.26 \\
\hline 2 & 100 & 10 & 60 & 31.79 \\
\hline 3 & 50 & 20 & 60 & 31.64 \\
\hline 4 & 100 & 20 & 60 & 31.98 \\
\hline 5 & 50 & 15 & 30 & 32.61 \\
\hline 6 & 100 & 15 & 30 & 32.81 \\
\hline 7 & 50 & 15 & 90 & 32.24 \\
\hline 8 & 100 & 15 & 90 & 33.82 \\
\hline 9 & 75 & 10 & 30 & 33.18 \\
\hline 10 & 75 & 20 & 30 & 28.97 \\
\hline 11 & 75 & 10 & 90 & 28.39 \\
\hline 12 & 75 & 20 & 90 & 34.13 \\
\hline 13 & 75 & 15 & 60 & 30.78 \\
\hline 14 & 75 & 15 & 60 & 30.53 \\
\hline 15 & 75 & 15 & 60 & 30.09 \\
\hline 16 & 75 & 15 & 60 & 30.68 \\
\hline 17 & 75 & 15 & 60 & 30.47 \\
\hline
\end{tabular}

Based on the results of single factor experiment, the concentration of onion juice, soaking time and spin-drying time were selected as three significant factors, and the whiteness value of fresh-cut carrot on the ninth day of storage was taken as the response value (Y) to optimize the experiment on the response surface.

\subsection{Model variance analysis}

Using Design-Expert 12.0 software to carry out multiple regression fitting for the data in Table 2, the regression equation obtained after the regression fitting of various factors was as follows:

$\mathrm{Y}=30.51+0.46 \mathrm{~A}+0.39 \mathrm{~B}+0.13 \mathrm{C}-$

$0.30 \mathrm{AB}+0.34 \mathrm{AC}+2.49 \mathrm{BC}+1.31 \mathrm{~A} 20.40 \mathrm{~B} 2+1.06 \mathrm{C} 2$.

The regression equation and coefficient were analyzed for significance, as shown in Table 3.

Table3. Significance analysis results of response surface regression model

\begin{tabular}{|c|c|c|c|c|c|c|}
\hline $\begin{array}{l}\text { Source of } \\
\text { Variance }\end{array}$ & Sum of squares & $\begin{array}{l}\text { Degree of } \\
\text { freedom }\end{array}$ & Mean square & $\mathrm{F}$ & $\mathrm{P}$ & Significance \\
\hline Model & 41.38 & 9 & 4.60 & 110.77 & $<0.0001$ & $* *$ \\
\hline A & 1.67 & 1 & 1.67 & 40.12 & 0.0004 & $* *$ \\
\hline $\mathrm{B}$ & 1.20 & 1 & 1.20 & 28.94 & 0.0010 & $* *$ \\
\hline $\mathrm{C}$ & 0.13 & 1 & 0.13 & 3.07 & 0.1231 & $*$ \\
\hline $\mathrm{AB}$ & 0.35 & 1 & 0.35 & 8.53 & 0.0223 & \\
\hline $\mathrm{AC}$ & 0.48 & 1 & 0.48 & 11.47 & 0.0116 & \\
\hline $\mathrm{BC}$ & 24.75 & 1 & 24.75 & 596.35 & $<0.0001$ & \\
\hline
\end{tabular}




$\begin{array}{cccccc}\mathrm{A}^{2} & 7.17 & 1 & 7.17 & 172.77 & <0.0001 \\ \mathrm{~B}^{2} & 0.67 & 1 & 0.67 & 16.03 & 0.0052 \\ \mathrm{C}^{2} & 4.69 & 1 & 4.69 & 112.92 & <0.0001 \\ \text { Residual } & 0.29 & 7 & 0.042 & & \\ \text { Lack of Fit } & 0.010 & 3 & 3.442 \mathrm{E}-003 & 0.049 & 0.9836 \\ \text { Pure error } & 0.28 & 4 & 0.070 & & \\ \text { Sum } & 41.67 & 16 & & & \end{array}$

Note: ${ }^{* *}$ The difference is extremely significant $(P<0.01) ;{ }^{*}$ The difference is significant $(P<0.05) ; \quad \mathrm{R}^{2}=0.9930, \quad \mathrm{R}^{2}{ }_{\mathrm{Adj}}=0.9841$

It could be seen from Table 3 that the regression of this model was extremely significant $(\mathrm{P}<0.0001)$, and the loss of fit term $\mathrm{P}=0.9836>0.05$, indicating that the loss of fit of this equation was not significant. And the results of model were $\mathrm{R}^{2}=0.9930$ and $\mathrm{R}^{2} \mathrm{Adj}=0.9841$, which indicated the model has a good fitting degree to the experiment and the linear relationship between the independent variable and the response value was significant. This test method was reliable and can be used in the prediction of the optimization experiment of onion juice treatment of fresh-cut carrot. The $P$ value analysis in Table 3 showed that the ranking of factors affecting the whiteness value is $\mathrm{A}>\mathrm{B}>\mathrm{C}$, that was, onion juice concentration $>$ soaking time $>$ spin-drying time within the selected factor level. Through response surface optimization, the optimal processing conditions for freshcut carrots treated with onion juice were as follows: the concentration of onion juice was $75 \%$, soaking time was $15 \mathrm{~min}$, and spin-drying time was $60 \mathrm{~s}$, and the predicted the whiteness value of fresh-cut carrot was 30.51 .

\subsection{Analysis of interaction of response surface factors and determination of optimal process conditions}

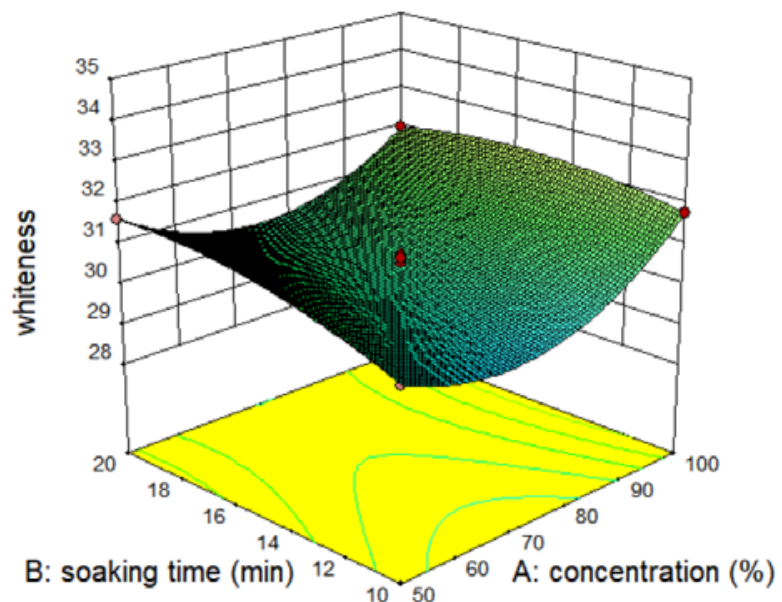

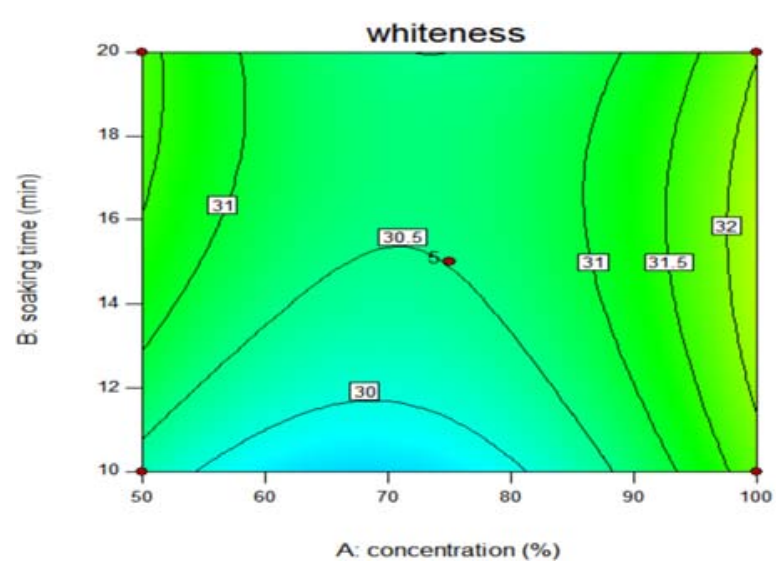

Figure 4. Response surface methodology for effects of soaking time and concentration on whiteness of fresh-cut
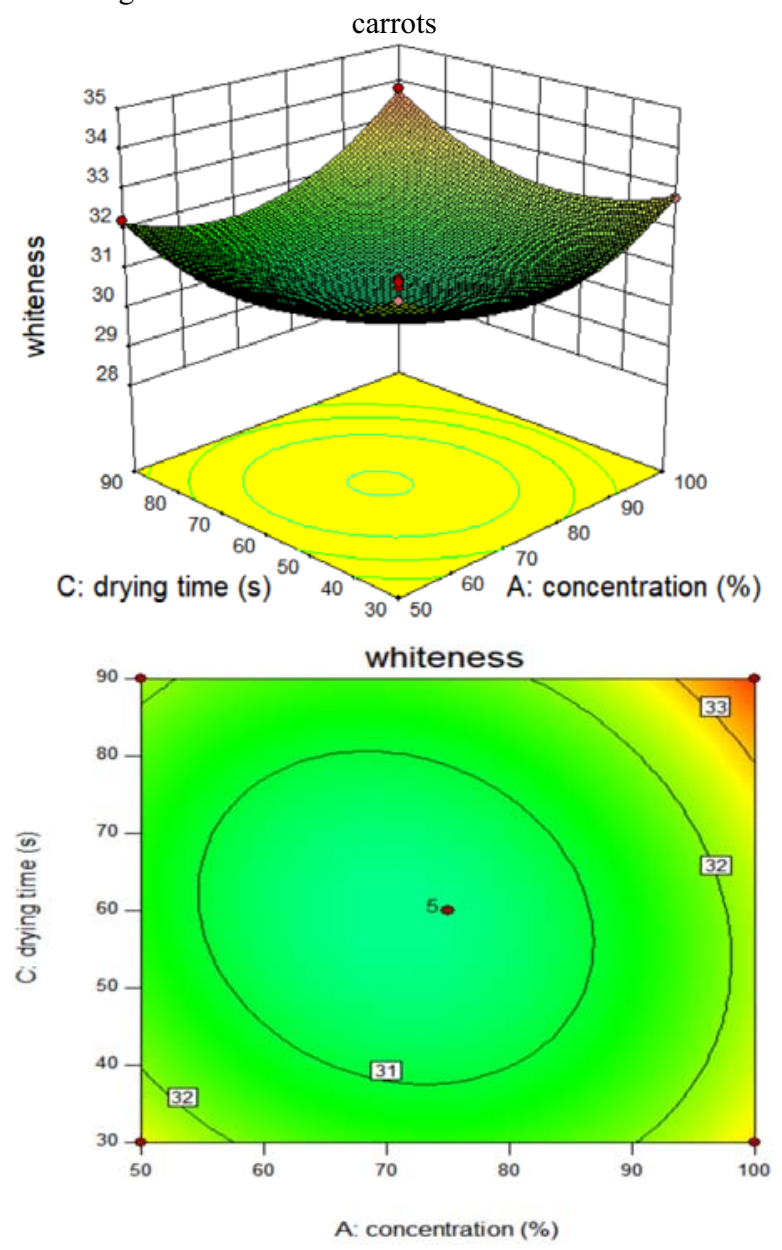

Figure 5. Response surface methodology for effects of drying time and concentration on whiteness of fresh-cut carrots 

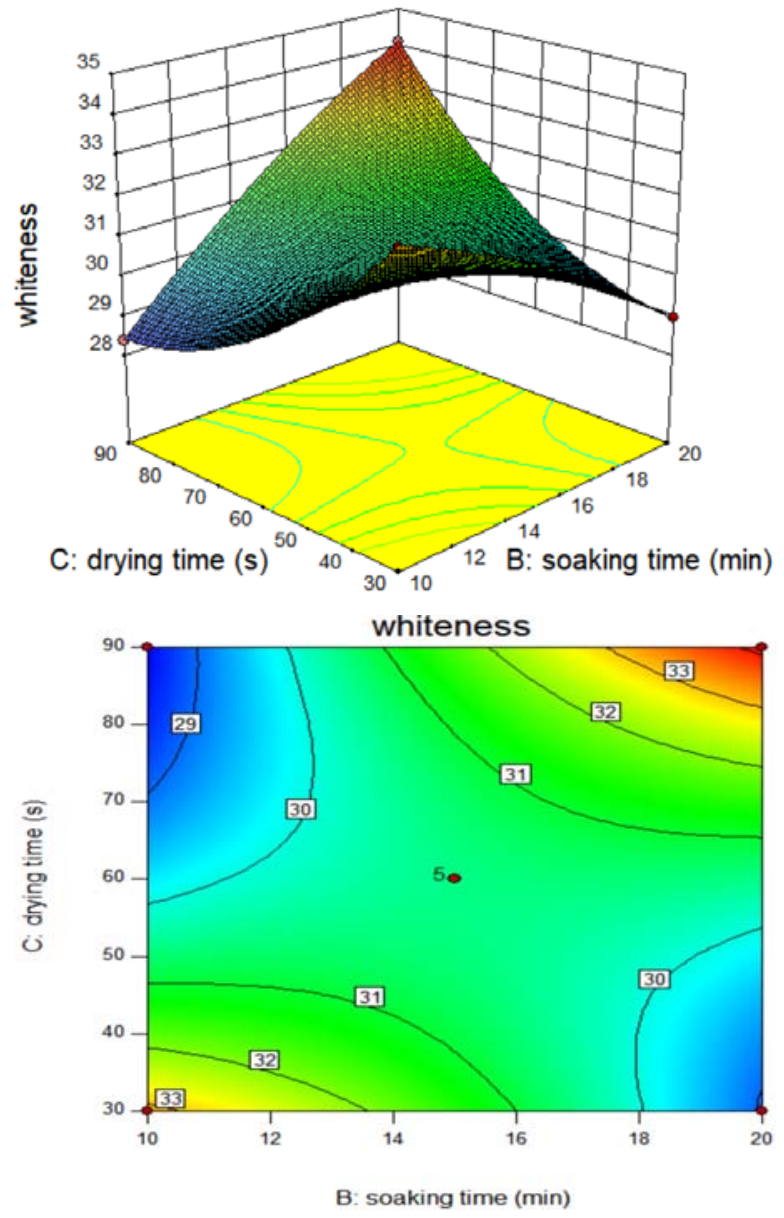

Figure 6. Response surface methodology for the effects of drying time and soaking time on the whiteness of fresh-cut carrots

Figure 4, the response surface figure and height contour shape of soaking time and concentration on the whiteness value(Y), the shape of contour was close to elliptic, indicating that the interaction effect between the soaking time of fresh-cut carrots and the concentration of onion juice was good. Figure 5, the response surface plot and high contour plot of concentration and spin-drying time to whiteness value (Y), the shape of contour plot was close to an elliptic, illustrating that two factors of different concentrations of onion juice and different spin-drying time had a strong interaction. The contour map of Figure 6 was close to a circle, indicating that the interaction between fresh-cut carrot soaking time and different spindrying time was poor. Through response surface optimization, the optimal processing conditions for freshcut carrots treated with onion juice were as follows: the concentration of onion juice was $75 \%$, soaking time was $15 \mathrm{~min}$, and drying time was $60 \mathrm{~s}$. The predicted whiteness value of fresh-cut carrots was 30.51 .

\subsection{Verification tests and results of the optimal process conditions}

\subsubsection{Changes in whiteness value of fresh-cut carrots during storage}

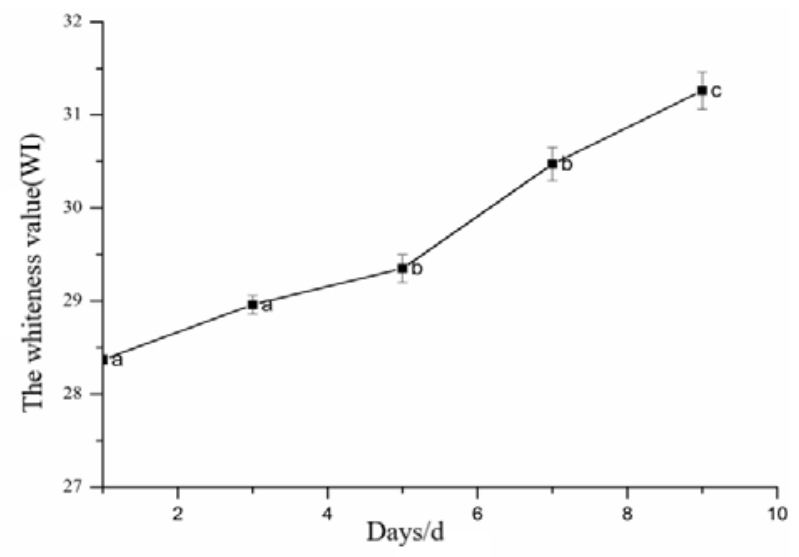

Figure 7. Changes of whiteness of fresh-cut carrots during storage

As can be seen from Figure 7, the whiteness value of freshcut carrots showed a trend of gradual increase during storage. On the ninth day, the whiteness value of fresh-cut carrots was $31.26 \pm 0.5$, which was close to the predicted value of 30.51 , indicating that the model was reliable.

\subsubsection{Changes in PAL activity during storage of fresh-cut carrots}

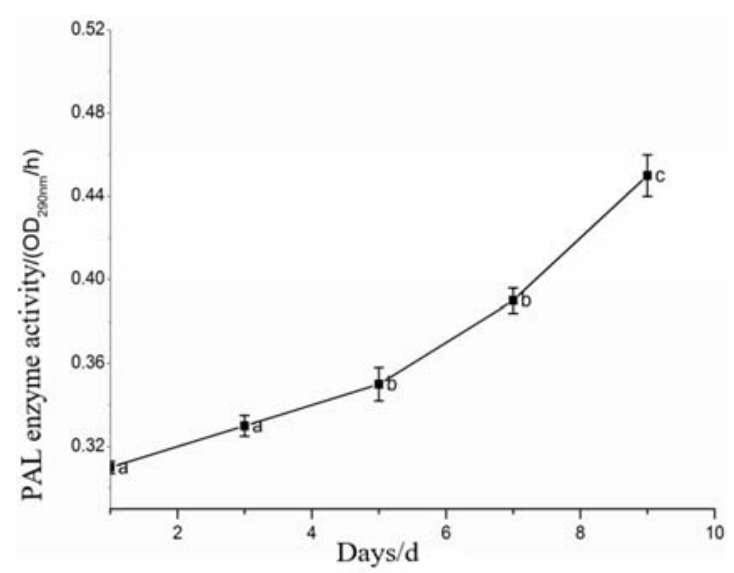

Figure 8. Changes of PAL activity of fresh-cut carrots during storage

It can be seen from Figure 8 that the PAL activity of freshcut carrot showed a trend of gradual increase during storage. Phenylalanine ammonia-lyase (PAL) was the first step of phenylpropane biosynthesis pathway and one of the key enzymes in lignin synthesis ${ }^{[8]}$. Compared with the results of Fan Teng ${ }^{[9]}$, the experiment inhibiting the whitening of fresh-cut carrots and the change of PAL activity in this study during storage was lower than that in Fan Teng' experiment, indicating that the technology in this study had a certain inhibitory effect on the PAL enzyme of fresh-cut carrots. 


\subsubsection{Changes in lignin content of fresh-cut carrots during storage}

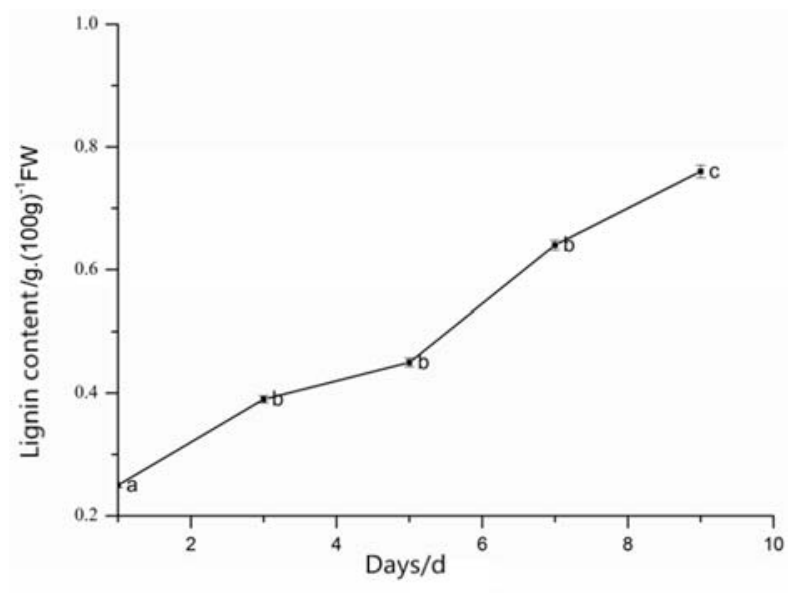

Figure 9. Changes of lignin content in fresh-cut carrots during storage

As the storage days increased, Figure 9 showed that the lignin content in fresh-cut carrots had an upward trend. The increase of lignin content also improved the whiteness value of fresh-cut carrots to a certain extent. At the ninth day of storage, lignin content in fresh-cut carrots was 0.71 $\mathrm{g} / 100 \mathrm{~g}$. In the research on the inhibition of whitening of fresh-cut carrots by Fanteng, the lignin content of freshcut carrots was $0.76 \mathrm{~g} / 100 \mathrm{~g}$ at the ninth day of storage, higher than the $0.71 \mathrm{~g} / 100 \mathrm{~g}$ in this study, which indicated that the technology in this study could reduce the lignin content of fresh-cut carrots during storage, and the effect was better.

\section{5 conclusion}

In this study, fresh carrot and onion were used as experimental materials to investigate the whitening of fresh-cut carrot during storage. A single factor test was designed to screen the optimal conditions for the treatment of fresh-cut carrots with onion juice. Based on the single factor test, the response surface was designed. The whiteness value was taken as the main reference index to optimize the processing parameters of fresh-cut carrots with onion juice, and the optimal processing parameters were obtained: Onion juice concentration was $75 \%$, the soaking time of $15 \mathrm{~min}$, spin-drying time for $60 \mathrm{~s}$. Under these conditions, the theoretical value of fresh-cut carrots was 30.51 , and the actual whiteness value was $31.26 \pm 0.5$. After verification, the model was established and the fit was good. The quality of fresh-cut carrot treated under these conditions was better during storage, which provided some scientific parameters for the study on the inhibition of whitening of fresh-cut carrots, and laid a foundation for onion juice to better inhibit whitening of fresh-cut carrots.

\section{Acknowledgement}

Beijing Municipal Science and Technology Commission Project: Vegetable Emergency Support Technology
Integration and Technology Demonstration (Z201100008020002)

\section{Reference}

1. Fan, T., Dong, H.Z., Wang, Z.S. (2011) Studies on the characteristics and inhibition conditions of peroxidase and phenylalanine ammonia-lyase in carrot. J. Chinese Journal of Food Science and Technology, 11(07): 22-28.

2. Ren, L.F. (2014) Study on quality change and preservation technology of fresh-cut carrot during storage. Hebei: Hebei Normal University of Science and Technology.

3. Chen, C., Hu, W.Z., Zhang, R.D., et al. (2018) Effects of hydrogen sulfide on the surface whitening and physiological responses of fresh-cut carrots. J. Journal of the science of food and agriculture, 98 (12) : 4726-4732.

4. Wang, Z.H. (2007) Study on extraction and preservation effect of onion essential oil. Hubei: Huazhong Agricultural University.

5. Bolin, H.R., Huxsoll, C.C. (1991) Control of minimally processed carrots (Daucus carotova) surface discoloration caused by abrasion peeling. J. Food Science, 56(2): 416.

6. Yu, J.X., Hu, W.Z., Zhao, MR., et al. (2019) Chinese Association of Food Science and Technology. In: The 16th Annual Meeting of the Chinese Association of Food Science and Technology and the 10th Sino-US Food Industry High-level Forum Paper Abstracts. Beijing. Pp. 449.

7. Li, Z.G., Gong, M. (2008) A new method for the determination of peroxidase activity in plants. J. Plant Physiology Communications, 44 (2) : 323-324.

8. Howard, L.R., Griffin, L.E. (1993) Lignin formation and surface discoloration of minimally processed carrot stick. J. Food Science, 58(5): 1065-1067.

9. Wang, Z., Wang, Z.S. (2011) Effect of sodium alginate composite coating on whitening of fresh-cut carrot. J. Food \& Fermentation Industry, 37(1): 206210. 